\title{
A PC Program for Estimating Measurement Uncertainty for Aeronautics Test Instrumentation
}

Philip Z. Blumenthal

NYMA, Inc.

Brook Park, Ohio

July 1995

Prepared for

Lewis Research Center

Under Contract NAS3-27186
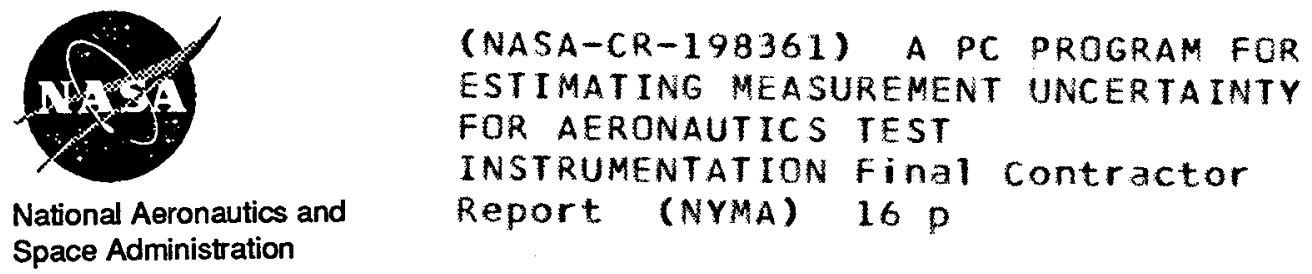


\section{A PC PROGRAM FOR ESTIMATING MEASUREMENT UNCERTAINTY FOR AERONAUTICS TEST INSTRUMENTATION}

Philip Z. Blumenthal

NYMA, Inc.

Engineering Services Division

Brook Park, Ohio 44142

\begin{abstract}
$\underline{\text { Abstract }}$
A personal computer program was developed which provides aeronautics and operations engineers at Lewis Research Center with a uniform method to quickly provide values for the uncertainty in test measurements and research results. The software package used for performing the calculations is Mathcad 4.0 , a Windows version of a program which provides an interactive user interface for entering values directly into equations with immediate display of results. The error contribution from each component of the system is identified individually in terms of the parameter measured. The final result is given in common units, SI units, and percent of full scale range. The program also lists the specifications for all instrumentation and calibration equipment used for the analysis. It provides a presentation-quality printed output which can be used directly for reports and documents.
\end{abstract}

\section{Nomenclature}

B'n: Bias component of error

B: Bias limit estimate

$\mathrm{j}$ : Number of measurement variables

$\mathrm{N}$ : Number of tests (measurement sets) averaged to obtain a result
S'n: Precision component of error

S: Precision limit of error

$\mathrm{U}$ : Uncertainty estimate

$\Theta$ : $\quad$ Sensitivity coefficient (partial derivative of result with respect to a variable)

$\sigma: \quad$ Population standard deviation

Subscripts:

i: Mathcad range variable

RSS: Root-sum-square

$\mathrm{x}: \quad$ Measured variable

$\mathrm{y}: \quad$ Measured variable

(other terms are defined in the comment column for the program examples included)

\section{Introduction}

In order for valid conclusions to be drawn from the results of research experiments, it is vital that an uncertainty analysis be performed to determine the interval about the result in which the true value is thought to lie with a certain degree of confidence. However, the estimated errors reported for similar 
research tests by different experimenters may differ substantially because of the methodology, assumptions, or data base used. Different procedures may be used because of the proliferation of standards and guidelines which have been published by technical organizations such ANSI/ASME ${ }^{1}, \mathrm{ISO}^{2}, \mathrm{AGARD}^{3}, \mathrm{NIST}^{4}$ and NASA ${ }^{5}$ in recent years. Although there are efforts occurring at present to harmonize the principles of the ASME model (Performance Test Code 19.1) and the ISO model (Guide to the Expression of Uncertainty in Measurement) into a new U. S. National Standard on Measurement Uncertainty, any methodology described by one of the present standards is currently accepted.

Another cause of differing results is due to the instrumentation specification data and assumptions used by the experimenter. Manufacturer's performance specifications for data system equipment require proper interpretation or knowledge of information, such as the manufacturer's testing process, which is not usually available in the written specification. Often, the time span (i.e., 8 hours, one month, one year) that is covered for each stated error source is not indicated, as well as the confidence limits or standard deviations (i.e., 1, 2, or $3 \sigma$ ) within which the stated error is contained. When a specification for amplifier noise is provided, it is only valid when it is adjusted for the particular gain and bandwidth used in the application.

In many instances, the experimenter may only consider the intrinsic error specifications given by the manufacturer, such as gain accuracy, offset, nonlinearity, hysteresis, repeatability, and noise, and neglect to include application-related performance specifications such as temperature coefficients, reference pressure changes, common mode rejection, source current and crosstalk.

Another factor to be considered is the uncertainty due to the equipment and methods used by the calibration laboratory. Laboratory calibrations are typically performed to reduce the total measurement uncertainty by providing traceability to national standards. It should be recognized that when only a single calibration is performed, there is no data scatter in the calibration curve provided, and all calibration process random errors (such as repeatability and noise) are permanently fossilized into the systematic (bias) error. Often, only the uncertainty of the reference standard is accounted for and other sources of error, such as the uncertainties in the transducer readout system used in the calibration facility, are ignored.

This paper describes a PC program that was developed in order to provide aeronautics and operations engineers at Lewis Research Center with a uniform methodology which can quickly provide quantitative values for estimating uncertainty in measurements. The software package chosen was Mathcad 4. $0^{11}$, a Windows version of a program which provides an interactive interface which allows the user to enter values directly into equations with immediate display of results. Readonly files were written for the standard types of instrumentation and data acquisition systems used in the aero test facilities and for the data reduction equations most commonly used.

\section{Program Assumptions}

The method to calculate uncertainty for these files is consistent with the concepts developed and evolving in the international standards with enhancements most commonly accepted, and is in compliance with the recent NASA Metrology - Calibration \& Measurement Process Guidelines ${ }^{5}$. For each measurement process, all likely elemental sources of error are identified and classified as either Systematic (B'n) or Precision (S'n) depending on their effect on the data. Systematic errors bias all data samples and cannot be observed in the data; they must be estimated using either good engineering judgement and experience, manufacturer's specifications, or other information. The Systematic or Bias Limit (B) is the experimenter's $95 \%$ confidence estimate of the band within which the mean value would fall if the experiment were repeated many times with the same equipment and test conditions. Precision or random errors are those that cause scatter in the data and are often estimated via statistical analysis of repeat measurements over an appropriate time interval. For the measurement processes evaluated in these files the distribution of these errors is assumed to be approximated by a normal (Gaussian) and symmetrical 
distribution around the mean. A sufficient number of data samples $(\geq 10)$ are averaged by the data acquisition to approximate the interval which should include $95 \%$ of individual samples by multiplying the standard deviation of the total data set (S) by a coverage factor of 2 .

To obtain the Total Uncertainty evaluated by the Root-Sum-Square method $\left(U_{R S S}\right)$, the estimates of B and $S$ are combined with the equation,

$$
U_{R S S}=\sqrt{(B)^{2}+(2 S / \sqrt{N})^{2}}
$$

The term $\sqrt{\mathrm{N}}$ is used to account for the reduction of random error when multiple experiment repetitions are averaged into a result. The manufacturer's specifications for systematic limits used in these files are assumed to be at a $3 \sigma(\sim 99 \%)$ confidence level (unless other data is available) which provides a theoretical confidence level for $U_{\text {RSS }}$ of about $97.5 \%$. In order to account for the difficulty in predicting environmental conditions, however, a more conservative value of $2 \sigma(95 \%)$ is quoted for the overall uncertainty. This provides an appropriate level of confidence in the uncertainty estimates for the types of tests performed in aero facilities.

For the files used to evaluate the uncertainty of results in data reduction equations, an engineering analysis was used to determine the systematic errors which are correlated for the type of measurement system used. It was assumed that all precision errors are uncorrelated, although there are some special cases where this is not true, as discussed by Hudson, et $\mathrm{al}^{6}$. The value for the term $\sqrt{\mathrm{N}}$ requires an assessment of the number of data sets that are averaged to obtain a result. Since this requires a very careful examination of the total measurement and data reduction process $^{7}$, a conservative value of one (1) is usually chosen unless the experimenter is certain that all data values which are averaged together are truly random samples from the total data set with all precision error sources having had an opportunity to influence the result.

\section{Measurement System Files}

The group of data files used with this Mathcad program are installed on a shared drive (with read-only protection) on the Local Area Network Server (DIMS) used by the Aeropropulsion Facilities and Experiments Division (AFED). An index is provided on a server file to identify the data files available. A listing and detailed description of the files is provided in AFED Preliminary Information Reports ${ }^{9}$. The selected data files are downloaded to the hard drive or removable disk on the engineer's office PC for computation and printout. Measurement instrumentation, data acquisition system and aerodynamic equation files can be linked together in order to propagate the elemental errors in the measurements through the data reduction equation, thereby generating the bias and precision errors and the uncertainty estimate for the experimental result.

The data files that were written for the measurement and data acquisition systems were designed specifically for the systems and practices in current use at NASA Lewis and should not be used by other organizations without careful examination of the factors and values given. Also, when actual data is available from a test or when a system is being used in a unique manner, the best data available should be used.

Each of the files, when retrieved into the Mathcad program, provides a page for entry of the numeric values for the application, one or more pages of calculations of the elemental bias and precision errors and total uncertainty estimate, and a final page listing the standard assumptions for the instrument specifications and error source values. Data files are currently available or are planned for the following instrumentation:

- Electronically scanned pressure systems PSI, Inc Model 780B \& Model 8400; rackmount or miniature modules

- Escort D/D+ (Lewis's facility DAQ systems) Neff Model 400, 100/200, 600, and 470 mux/amp system

- Thermocouples

Type K, T, J, E, and P13

- High output (capacitive type) pressure transducers Setra Model 204, 204D, 239, 270, and 370 
- Strain gage pressure transducers

Lewis Instrument Pool standard models

- Miniature semiconductor strain gage transducers

- Standard load cells

- Liquid turbine type flowmeters

Lewis Instrument Pool standard models

A typical measurement file is shown in Example A. On the first page, the numeric values used in the test are entered in the placeholders for both the data acquisition system (Escort D/Neff 400) and the thermocouple system, since this is the arrangement commonly used. The calculations on the second page are used to convert the test temperature (T_F) and the reference temperature ( $\left.T \_R E F\right)$ to a millivolt output using the conversion polynomial from NIST Monograph 175. On the third page, this millivolt value is used to determine a sensitivity factor (SEN) used for calculations of the elemental bias (B'n) and precision error ( $\left.S^{\prime} n\right)$ estimates in temperature $\left({ }^{\circ} \mathrm{F}\right)$ and the Uncertainty limit $\left(\mathrm{U}_{\mathrm{RSS}}\right)$ in temperature $\left({ }^{\circ} \mathrm{F} \&{ }^{\circ} \mathrm{C}\right)$ and $\%$ of test temperature. The term $\sqrt{\mathrm{N}}$ is assumed to be 1 for thermocouple files. The fourth page lists the specifications for this measurement system.

\section{Data Reduction Equation Files}

In most experimental programs, the measured values of different variables are combined using a number of data reduction equations to obtain test conditions and performance results. The methods used to propagate the errors in the measurements through these equations to obtain an estimate of the uncertainly limit in the results are given in detail in the references ${ }^{1,5,6}$. For each case, not only must a sensitivity factor for the equation be calculated for the systematic and precision limit of each variable, but an engineering analysis should also be made of the elemental systematic or precision uncertainties that are correlated, that is, they arise from the same source. For a case where an experimental result, $r$, is a function of two measured variables, $x$ and $y$, and the systematic uncertainties $\mathrm{B}^{\prime}{ }_{\mathrm{x}}$ and $\mathrm{B}_{\mathrm{y}}{ }_{\mathrm{y}}$ are the systematic uncertainties in $\mathrm{x}$ and $\mathrm{y}$ that arise from the same source,

$$
B_{r}=\left[\left(\Theta_{x} B_{x}\right)^{2}+\left(\Theta_{y} B_{y}\right)^{2}+2 \Theta_{x} \Theta_{y} B_{x}^{\prime} B_{y}^{\cdot}\right]^{1 / 2}
$$

where $\Theta_{x}=\partial r / \partial x$ and $\Theta_{y}=\partial r / \partial y$

Usually, the elemental error for the precision uncertainties in $\mathrm{x}$ and $\mathrm{y}$ are uncorrelated. Thus, the sample standard deviation in the result is,

$$
S_{r}=\left[\left(\Theta_{x} S_{x}\right)^{2}+\left(\Theta_{y} S_{y}\right)^{2}\right]^{1 / 2}
$$

With a coverage factor of 2 and $N_{r}$ sets of measurements obtained over an appropriate time period, the uncertainty estimate of the result is,

$$
U_{r}=\sqrt{\left(B_{r}\right)^{2}+\left(2 S_{r} / \sqrt{N_{r}}\right)^{2}}
$$

In Example B, a Mach number file is combined with an ESP system file to obtain values of uncertainty in the Mach number for a series of test conditions. In this case, the bias errors in $B^{\prime} 1, B^{\prime} 2, B^{\prime} 3$, which are associated with the common Digiquartz calibration transducer, and $\mathrm{B}^{\prime} 4$, which is a common module atmospheric reference. The partial derivatives for the Mach number equation were obtained with Mathcad's Symbolic Operator by setting the cursor on the variable to be evaluated and choosing the Differentiate on Variable command from the Symbolic menu. This must be performed before the range variable (i) is added to the function.

Data files are currently available or are planned for a variety of data reduction equations including Mach number, dynamic pressure, flow angularity $(\alpha \& \beta)$, and mass flow (venturi, orifice plate).

\section{$\underline{\text { Summary }}$}

This program has provided the experimenter with a user friendly method to estimate measurement errors for any particular set of test conditions. Since it identifies the error contribution from each component of the system, it provides insight into potential improvement areas where productive actions may be taken to reduce uncertainties. Thus, many "what-if" changes in the 
instrumentation system design may be tried, and the results instantly determined. It assures that a uniform data base and methodology is used for all test facilities and it serves to document the specifications for all instrumentation and calibration equipment used in the analysis for future reference. It also provides a reportquality printed output.

\section{References}

${ }^{1}$ American National Standards Institute/American Society of Mechanical Engineers, Measurement Uncertainty, PTC19.1-1985 Part 1, ASME, 1986.

${ }^{2}$ Guide to the Expression of Uncertainty in Measurement, International Organization for Standardization, Geneve, Switzerland,1993.

${ }^{3}$ Advisory Group for Aerospace Research \& Development, Assessment of Wind Tunnel Data Uncertainty, AGARD-AR-304, 1994.

${ }^{4}$ Taylor, B.N. and Kayatt, C.E., Guidelines for Evaluating and Expressing the Uncertainty of NIST Measurement Results, NIST Technical Note 1297, 1993.

${ }^{5}$ NASA Metrology and Calibration Working Group, Metrology - Calibration and Measurement Process Guidelines, NASA Reference Publication 1342, June, 1994.
${ }^{6}$ Hudson, S.T., Bordelon, W.J. Jr, and Coleman, H.W., "Effect of Correlated Precision Errors on the Uncertainty of a Subsonic Venturi Calibration," AIAA Paper 95-0797, 33rd AIAA Aerospace Sciences Meeting and Exhibit, Reno, NV, Jan. 9-12, 1995

${ }^{7}$ McCarty, P.E., "Practical Considerations in Applying $\sqrt{\mathrm{N}}$ when Assessing Measurement Uncertainties," Proceedings of the 41st International Instrumentation Symposium of the ISA, May, 1995.

${ }^{8}$ Coleman, H.W. and Steele, W.G. Jr., Experimentation and Uncertainty Analysis for Engineers, John Wiley and Sons, New York, 1989.

${ }^{9}$ Blumenthal, P.Z., A Program to Calculate Measurement Uncertainty for Instrumentation Used in AFED Test Facilities (Part 1), Aeropropulsion Facilities \& Experiments Division, Preliminary Information Report \#53, NASA Lewis Research Center, Cleveland, OH, October, 1994.

${ }^{10}$ Blumenthal, P.Z., Additional Program Files for Calculation of Measurement Uncertainty for Instrumentation and Data Reduction Equations Used in AFED Test Facilities (Part 2), Aeropropulsion Facilities \& Experiments Division, Preliminary Information Report \#TBD, NASA Lewis Research Center, Cleveland, OH, Due to be published September, 1995.

"Mathcad 4.0 User's Guide, Windows Version, MathSoft, Inc, Cambridige, MA, 1993. 


\section{Example A}

\section{Measurement Uncertainty Program}

C) THERMOCOUPLES (including ESCORT/Neff 400 DAQ Syst)

1.) Type K (Chromel-Alumel) (File TCK001.MCD)

$$
\mathrm{F}:=\mathrm{R} \quad \mathrm{C}:=\mathrm{K} \quad \mu \mathrm{V}:=\mathrm{mV} \cdot 10^{-3}
$$

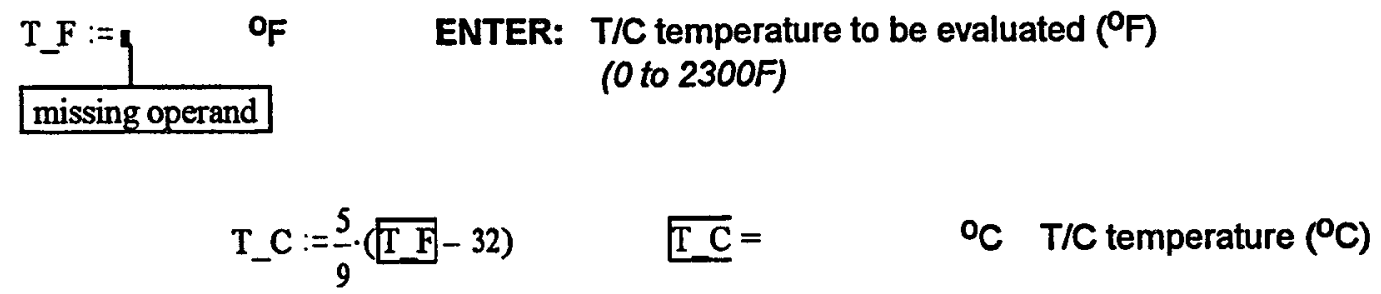

T_REF : $=\quad$ OF $\quad$ ENTER: 150 for 150 of Reference oven or $\underline{75}$ for Isothermal Block

missing operand

$\mathrm{MV}:=\mathbf{q} \cdot \mathrm{mV}$

ENTER: ESCORT D/D+ Millivolt Range $(+/-5,10,20,40,80)$

missing operand

$t:=$ of

ENTER: Temperature excursion of ESCORT System from calibrated temp $\left({ }^{\circ} \mathrm{F}\right)$ (typical value, $5^{\circ} \mathrm{F}$ )

CMV := V

ENTER: Common Mode Voltage in Test Cell (Volts)

(typical value, $5-10$ volts)

CSTK $:=\mathbf{Y}$
missing operand

ENTER: Voltage difference between consecutively scanned channels (Volts) (if less than $100 \mathrm{mV}$, enter O)

$$
\mathrm{G}:=\frac{10240 \cdot \mathrm{mV}}{\sqrt{\mathrm{MV}}} \quad \overline{\mathrm{G}}=\quad \text { Neff Amplifier Gain }
$$


Page C.1.2 TYPE K T/C Conversion Polynominal (Temp to $\mathrm{mV}$ )

\section{OC to $1372 C$}

$$
\begin{aligned}
& a_{0}:=1.185976 \cdot 10^{2} \\
& c_{4}:=3.1840945719 \cdot 10^{-7} \\
& a_{1}:=-1.183432 \cdot 10^{-4} \\
& c_{5}:=-5.6072844889 \cdot 10^{-10} \\
& c_{0}:=-1.7600413686 \cdot 10^{1} \\
& c_{6}:=5.6075059059 \cdot 10^{-13} \\
& c_{1}:=3.8921204975 \cdot 10^{1} \\
& c_{7}:=-3.2020720003 \cdot 10^{-16} \\
& c_{2}:=1.8558770032 \cdot 10^{-2} \\
& c_{8}:=9.7151147152 \cdot 10^{-20} \\
& c_{3}:=-9.9457592874 \cdot 10^{-5} \\
& c_{9}:=-1.2104721275 \cdot 10^{-23} \\
& \mathrm{n}:=9 \\
& E_{-} 1:=\left[\left(\sum_{i=0}^{n} c_{i} \cdot \sqrt{\mathbb{T - C ^ { i }}}\right)+\alpha_{0} \cdot e^{\alpha_{1} \cdot(\sqrt{\mathbb{C}}-126.9686)^{2}}\right] \cdot \mu \mathrm{V} \\
& E\left[-E^{1}=-\mu \mathrm{V}\right.
\end{aligned}
$$

\section{$-270 \mathrm{C}$ to $0 \mathrm{C}$}

$$
\begin{aligned}
& c_{0}:=0 \\
& c_{6}:=-5.7410327428 \cdot 10^{-10} \\
& c_{1}:=3.9450128025 \cdot 10^{1} \\
& c_{7}:=-3.1088872894 \cdot 10^{-12} \\
& c_{2}:=2.3622373598 \cdot 10^{-2} \\
& c_{8}:=-1.0451609365 \cdot 10^{-14} \\
& c_{3}:=-3.2858906784 \cdot 10^{-4} \\
& c_{9}:=-1.9889266878 \cdot 10^{-17} \\
& c_{4}:=-4.9904828777 \cdot 10^{-6} \\
& c_{10}:=-1.6322697486 \cdot 10^{-20} \\
& c_{5}:=-6.7509059173 \cdot 10^{-8} \\
& \mathrm{n}:=10 \\
& E_{-} 2:=\sum_{i=0}^{n} c_{i} \cdot{ }^{\left[C^{i}\right.} \cdot \mu V \\
& \overline{E 2}=\cdot \mu \mathrm{V}
\end{aligned}
$$

E_REF :=if $\overline{\text { T REF }}<150,0.95 \cdot \mathrm{mV}, 2.66 \cdot \mathrm{mV}$ )

E_REF $=\cdot \mu \mathrm{V}$

E_3 : if $\left(\overline{\mathbb{T}[\mathrm{C}}<0, \sqrt{E 2}, \sqrt{\mathrm{E}_{1}}\right)$

$E \underline{E}=\cdot \mu \mathrm{V}$

$\mathrm{E}_{0}:=\sqrt{\mathrm{E} 3}-\overline{\mathrm{EREF}}$

$$
\mathbb{E}_{0}=\cdot m V
$$

Output at Eval Temp 


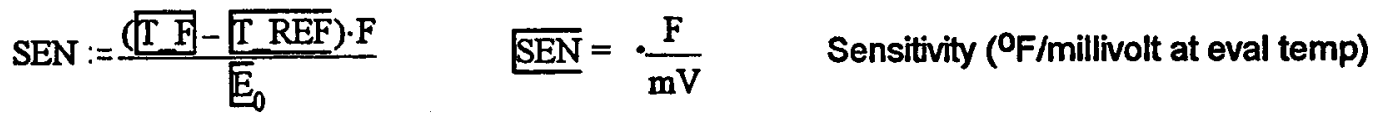

$$
\begin{aligned}
& \mathrm{B}^{\prime} 1:=\mathrm{if}\left(\mathrm { T } \left[\mathrm{F}<530,2 \cdot \mathrm{F}, 0.00375 \cdot[\mathrm{TF} \cdot \mathrm{F}) \quad \quad \quad \mathrm{B}^{\prime} 1=-\mathrm{F} \quad \text { Type } \mathrm{K} \text { Thermocouple error }\left({ }^{\circ} \mathrm{F}\right)\right.\right.
\end{aligned}
$$

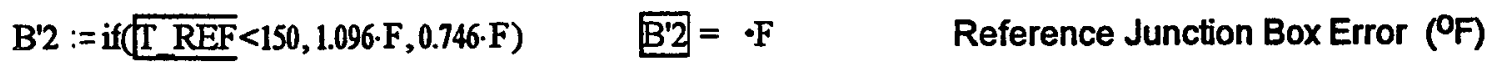

$$
\begin{aligned}
& \mathrm{B}^{\prime} 3:=(0.05 \cdot \% \cdot \overline{\mathrm{MV}}) \cdot \overline{\mathrm{SEN}} \quad \quad \overline{B^{\prime} 3}=\cdot \mathrm{F} \quad \text { Neff Gain Accuracy }
\end{aligned}
$$

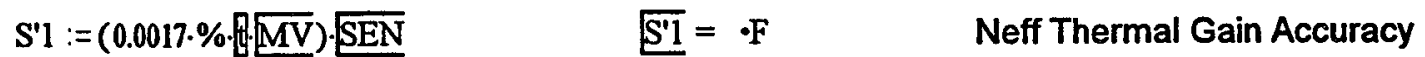

$$
\begin{aligned}
& B^{\prime} 4:=\left(0.02 \% \cdot \frac{\sqrt[M V]{M V}}{2 \cdot 2^{13}} \cdot \frac{1}{M V}\right) \cdot \sqrt{S E N} \quad \overline{B^{\prime} 4}=-F \quad \text { Neff Non-Linearity }
\end{aligned}
$$

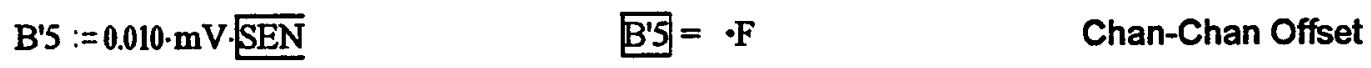

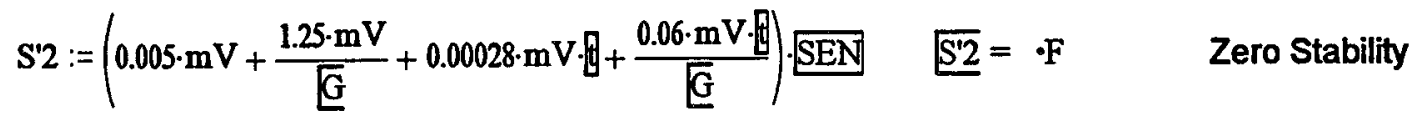

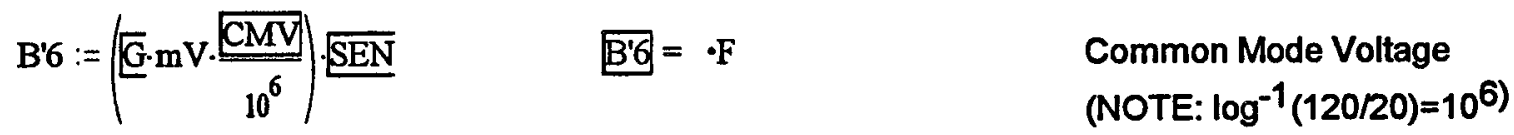

$$
\begin{aligned}
& \mathrm{B} 7:=\left(\overline{\mathrm{G}} \cdot \mathrm{mV} \cdot \frac{\overline{\mathrm{CSTK}}}{10^{6}}\right) \cdot \overline{\text { SEN }} \quad \text { B'7 }=\cdot \mathrm{F} \quad \text { Static Crosstalk } \\
& B^{\prime} 8:=\left(\frac{1}{2^{13}} \cdot \sqrt{M V}\right) \cdot \sqrt{S E N} \quad B=\cdot F \quad \text { Digitizing Error } \\
& \mathrm{S}^{\prime} 3:=\left[\sqrt{0.0085^{2}+\left(\frac{0.75}{\overline{\mathrm{G}}}\right)^{2}} \cdot \mathrm{mV}\right] \sqrt{\mathrm{SEN}} \quad \sqrt{\mathrm{S}^{\prime} 3}=\cdot \mathrm{F} \quad \text { Noise }(+1-3 \text { sigma }) \\
& B:=\sqrt{\left(\sqrt{\left.B^{\prime}\right]}\right)^{2}+\left(\sqrt{B^{\prime} 2}\right)^{2}+\left(\sqrt{B^{\prime} 3}\right)^{2}+\left(\sqrt{B^{\prime} 4}\right)^{2}+\left(\sqrt{B^{\prime} 5}\right)^{2}+\left(\sqrt{B^{\prime} 6}\right)^{2}+\left(\sqrt{B^{\prime} 7}\right)^{2}+\left(\sqrt{B^{\prime} 8}\right)^{2}} \quad B=\cdot F \\
& S:=\sqrt{{S^{\prime \prime} 1^{2}}^{2}+{\sqrt{S^{\prime}} 2^{2}}^{2}+{\sqrt{S^{\prime} 3}}^{2}} \quad[S=\cdot F
\end{aligned}
$$

Temperature Measurement Uncertainty

$$
\begin{aligned}
& \mathrm{U}_{\mathrm{RSS}}:=\sqrt{\sqrt{\mathrm{B}}^{2}+(2 \cdot \sqrt{\mathrm{S}})^{2}} \quad{\mathbb{\mathrm { U } _ { \mathrm { RSS } }}}_{\overline{\mathrm{R}}}=\cdot \mathrm{F} \quad+/- \text { Uncertainty }\left({ }^{\circ} \mathrm{F}\right) \\
& \widetilde{U}_{\overline{\mathrm{RSS}}}=\cdot \mathrm{C} \quad+1 \text { - Uncertainty }\left({ }^{\circ} \mathrm{C}\right)
\end{aligned}
$$

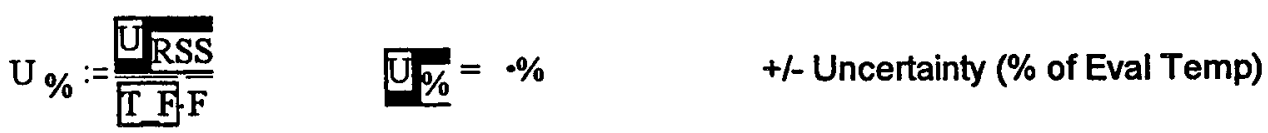


Type K T/C Conversion Polynominal - NIST Monograph 175

B'1 - ISA Type K Thermocouple Wire (Special)

$32 \mathrm{~F}$ to $530 \mathrm{~F} \quad+1-2.0{ }^{\circ} \mathrm{F}$

$530 \mathrm{~F}$ to $1400 \mathrm{~F} \quad+/-3 / 8 \%$ of $\mathrm{Rdg}$

$\mathrm{B}^{\prime} 2$ (150 F) - Thermocouple Reference Oven (U-48/U49)
$B^{\prime} 10:=0.25$
Oven Temp Error ( $\left.{ }^{\circ} \mathrm{F}\right)$
$B^{\prime} 11:=0.02$
PRT Error $\left({ }^{\circ} \mathrm{F}\right)$
$B^{\prime} 12:=0.03$
PRT Readout (Instrulab) Error ( $\left.{ }^{\circ} \mathrm{F}\right)$
$B^{\prime} 13:=0.7$
Thermocouple Output Error ( ${ }^{\circ} \mathrm{F}$ )
$B^{\prime} 14:=0.0128$
T/C Readout (Keithly 182) Error (F)
$B^{\prime} 15:=0.05$
Ice Point Error ( $\left.{ }^{\circ} \mathrm{F}\right)$
$B_{150}:=\sqrt{\left(B^{\prime} 10\right)^{2}+\left(B^{\prime} 11\right)^{2}+\left(B^{\prime} 12\right)^{2}+\left(B^{\prime} 13\right)^{2}+\left(B^{\prime} 14\right)^{2}+\left(B^{\prime} 15\right)^{2}} \quad B_{150}=0.746$

B`2 (75 F) - Thermocouple Reference Isothermal Block
$B^{\prime} 20:=1.0$
RTD Accuracy
$\mathrm{B}^{\prime 2} 21:=0.02$
PRT Error ( ${ }^{\circ}$ )
(PF) (Mfgr's spec is $0.5 \%$, waver to $1 \%$ granted $1 / 6 / 87$.
$B^{\prime} 22:=0.03$
PRT Readout (Instrulab) Error ( ${ }^{\circ} \mathrm{F}$ )
$\mathrm{B}^{\prime 23}:=0.4$
End to End Block Error (Specification) (oF)
$B^{\prime 2} 24:=0.2$
T/CStability Error (Specification) ( $\left.{ }^{\circ} \mathrm{F}\right)$
$B_{75}:=\sqrt{\left(B^{\prime} 20\right)^{2}+\left(B^{\prime} 21\right)^{2}+\left(B^{\prime} 22\right)^{2}+\left(B^{\prime} 23\right)^{2}+\left(B^{\prime} 24\right)^{2}} \quad B_{75}=1.096$

\section{Neff 400 Specifications}

B'3 - +/- (0.05\% FS)

$S^{\prime} 1-+1-(0.0017 \% \mathrm{FS} / \mathrm{F})$

$\mathrm{B}^{\prime} 4-+/-(0.02 \% \mathrm{FS}+1 / 2 \mathrm{LSB})$

B' $^{\prime}$ - $+/-0.010 \mathrm{mV}$

$\mathrm{S}^{\prime} 2$ - +/-(0.005 mVRTI + $\left.1.25 \mathrm{mVRTO}\right)+(0.00028 \mathrm{mV} / \mathrm{F} \mathrm{RTI}+0.06 \mathrm{mV} / \mathrm{F} \mathrm{RTO})$

$\mathrm{B}^{\prime} 6-80 \mathrm{~dB}$ plus gain (in $\mathrm{dB}$ ) to $120 \mathrm{~dB}$

B' $7-120 \mathrm{~dB}$

B' 8 - 1/2 LSB

$\mathrm{S}^{\prime} 3-\left[(0.0085 \mathrm{mV} \times \text { Gain })^{2}+(0.75 \mathrm{mV})^{2}\right] 1 / 2$
Gain Accuracy

Thermal Gain Accuracy

Non-Linearity Chan-Chan Offset

Zero Stability

Common Mode Rejection Static Crosstalk

Digitizing Error

Noise 


\section{Measurement Uncertainty Program}

\section{A) ESP SYSTEM}

1.) 780B System using Rackmount Modules (File ESP001.MCD)

$$
\text { psi }:=\frac{\text { lbf }}{\text { in }^{2}} \quad \mathrm{psf}:=\frac{\mathrm{psi}}{144} \quad \mathrm{kPa}:=\frac{\text { newton }}{\mathrm{m}^{2}} \cdot 1000
$$

$D:=15 \cdot p s i$

ENTER: Digiquartz Range $(6,15,23,30,45,65,100,300,500)$

t_l $1:=2$

ENTER: DQ temp excursion from calibrated temp ( ${ }^{\circ} \mathrm{F}$ )

(typical value for temp controlled box, 2)

$M:=5 \cdot p s i$

ENTER: Module Range $(1,2.5,5,10,15,30,45,100,250,500)$

M_t $:=1$

ENTER: Module sensor temp coeff factor (1 if S/N 1 to B02037 (9/93), 2 if S/N B02038 up)

$\mathrm{SF}:=1000 \cdot \frac{1}{\mathrm{psi}}$

ENTER: Scale Factor for module group (see Table 1)

t_ $2:=0$

$\mathbf{N}:=20$
$\mathrm{B}^{\prime} 5:=0 \cdot \mathrm{psi}$

ENTER: Module ref press change allowed between cals (psi) (typical value for atmospheric reference, 0.01)

ENTER: Module temp excursion allowed between cals ( ${ }^{\circ} \mathrm{F}$ ) (typical value, 3)

ENTER: Number of Data Sets that are averaged to obtain result (if a single data set is used, enter 1)

$k:=\operatorname{if}(D<15 \cdot p s i, 0.011,0.012) \quad k=0.012 \quad$ Cal lab DQ calib error coefficient

$Z_{\_} 1:=\mathrm{if}(\mathrm{M}<5 \cdot \mathrm{psi}, 0.05,0.02) \quad \mathrm{Z}_{-} 1=0.02 \quad \mathrm{Z}_{-} 2:=\mathrm{if}(\mathrm{M}<2.5 \cdot \mathrm{psi}, 0.008,0.004) \quad Z_{-} 2=0.004$

$\mathrm{Z} 3 \mathrm{3}:=\mathrm{if}\left(\mathrm{M}_{-} \mathrm{t}<2, \mathrm{Z}_{-} 1, Z_{-}{ }_{2}\right) \quad \mathrm{Z}_{-} 3=0.02 \quad$ Module thermal zero shift coeff

S_1 :=if(M<2.5.psi, 0.05,0.02) S_1 $=0.02$

S_2 : $=0.003$

S_3 : if $\left(M_{-} t<2, S_{-} 1, S_{-} 2\right) \quad$ S_3 $=0.02 \quad$ Module thermal span shift coeff 
Error Source Evaluation (NOTE: all errors are +/-)

780B System using Rackmount Modules

$$
\begin{aligned}
& B^{\prime} l:=k \cdot \% \cdot D \\
& B^{\prime} 1=0.0018 \cdot p s i \\
& B^{\prime} 2:=0.001 \cdot t_{-} 1 \cdot \% \cdot D \\
& \mathrm{~B}^{\prime 2}=0.0003 \cdot \mathrm{psi} \\
& B^{\prime 3}:=0.005 \cdot \% \cdot D \\
& \mathrm{~B}^{\prime} 3=0.00075 \text { psi } \\
& B^{\prime} 4:=0.005 \cdot \% \cdot D \\
& \text { B'4 }=0.00075 \text { psi } \\
& S^{\prime} 1:=0.005 \% \text { D } \\
& S^{\prime} 1=0.00075 \mathrm{psi} \\
& S^{\prime} 2:=0.005 \cdot \% \cdot D \\
& S^{\prime 2}=0.00075 \text { psi } \\
& S^{\prime} 3:=0.0005 \cdot \% \cdot D \\
& S^{\prime} 3=0.00008 \cdot p s i \\
& \text { S'4 : }=0.010 \cdot \% \cdot M \\
& \mathrm{~S}^{\prime} 4=0.0005 \mathrm{psi} \\
& S^{\prime} 5:=0.005 \cdot \% \cdot M \\
& S^{\prime} 5=0.00025 \text { psi } \\
& \text { B'5 }=0 \text { •psi } \\
& B^{\prime} 6:=Z_{-} 3 \cdot \% \cdot t \_2 \cdot M \\
& \mathrm{~B}^{\prime} 6=0 \text {-psi } \\
& \mathrm{B}^{\prime} 7=0 \text { psi } \\
& \mathrm{B}^{\prime} 8:=0.010 \cdot \% \cdot \mathrm{M} \\
& \mathrm{B}^{\prime} 8=0.0005 \cdot \mathrm{psi} \\
& S^{\prime} 6:=0.012 \cdot \% \cdot M \\
& \mathrm{~S}^{\prime} 6=0.0006 \mathrm{psi} \\
& S^{\prime} 7:=\frac{1}{S F} \\
& \mathrm{~S} 7=0.001 \mathrm{psi} \\
& \text { Cal Lab DQ calibration error } \\
& \text { DQ temp error } \\
& \text { Time base error } \\
& \text { Curve fit error (Digiquartz) } \\
& \text { Repeatibility (Digiquartz) } \\
& \text { Hysteresis } \\
& \text { (Digiquartz) } \\
& \text { Counter resolution (Digiquartz) } \\
& \text { ESP repeatability } \\
& \text { ESP hysteresis } \\
& \text { ESP reference pressure change } \\
& B:=\sqrt{\left(B^{\prime} 1\right)^{2}+\left(B^{\prime} 2\right)^{2}+\left(B^{\prime} 3\right)^{2}+\left(B^{\prime} 4\right)^{2}+\left(B^{\prime} 5\right)^{2}+\left(B^{\prime} 6\right)^{2}+\left(B^{\prime} 7\right)^{2}+\left(B^{\prime} 8\right)^{2}} \\
& B=0.00217 \cdot p s i \\
& S:=\sqrt{\left(S^{\prime} 1\right)^{2}+\left(S^{\prime} 2\right)^{2}+\left(S^{\prime} 3\right)^{2}+\left(S^{\prime} 4\right)^{2}+\left(S^{\prime} 5\right)^{2}+\left(S^{\prime} 6\right)^{2}+\left(S^{\prime} 7\right)^{2}} \\
& S=0.00167 \cdot p s i
\end{aligned}
$$

Pressure uncertainty

$$
\begin{aligned}
& U_{\text {RSS }}:=\sqrt{B^{2}+\left(\frac{2 \cdot S}{\sqrt{N}}\right)^{2}} \\
& \mathrm{U}_{\mathrm{RSS}}=0.00229 \cdot \mathrm{psi} \quad+/ \text { - Uncertainty (psi) } \\
& \mathrm{U}_{\mathrm{RSS}}=0.33044 \text { psf } \quad+/ \text {-Uncertainty (psf) } \\
& \mathrm{U}_{\%}:=\frac{\mathrm{U}_{\mathrm{RSS}}}{\mathrm{M}} \\
& \mathrm{U}_{\mathrm{RSS}}=0.01582 \cdot \mathrm{kPa} \quad+/ \text { - Uncertainty }(\mathrm{kPa}) \\
& U_{\%}=0.04589 \cdot \% \quad+/ \text { - Uncertainty (\% of Module Range) }
\end{aligned}
$$


Page M.1.1

\section{Mach Number Uncertainty (File Mach001.MCD)}

$$
\begin{aligned}
& \mathrm{BPt}:=\mathrm{B} \quad \mathrm{BPs}:=\mathrm{B} \quad \mathrm{B}=0.00217 \mathrm{psi} \quad \text { Systematic uncert. in total and static pressures } \\
& \mathrm{SPt}:=2 \cdot \frac{\mathrm{S}}{\sqrt{\mathrm{N}}} \quad \mathrm{SPt}=0.00075 \mathrm{psi} \quad \text { Precision uncert. in total pressure } \\
& \text { SPs }:=2 \cdot \frac{\mathrm{S}}{\sqrt{\mathrm{N}}} \quad \mathrm{SPs}=0.00075 \cdot \mathrm{psi} \quad \text { Precision uncert. in static pressure } \\
& \mathrm{BPc}:=\sqrt{\mathrm{B}^{\prime} 1^{2}+\mathrm{B}^{\prime} 2^{2}+\mathrm{B}^{\prime} 3^{2}+\mathrm{B}^{\prime} 5^{2}} \quad \mathrm{BPc}=0.00197 \mathrm{psi} \quad \text { Correlated bias errors } \\
& \text { BPtc }:=\text { BPc } \quad \text { BPtc }=0.00197 \cdot p s i \quad \text { Correlated bias errors in total } p \\
& \text { BPsc := BPc BPsc }=0.00197 \cdot \mathrm{psi} \quad \text { Correlated bias errors in static } \mathrm{p}
\end{aligned}
$$

\begin{tabular}{|c|c|}
\hline \multicolumn{2}{|l|}{$\mathbf{N r}:=4$} \\
\hline $\mathrm{n}:=12$ & $\mathrm{i}:=1$. \\
\hline $\mathrm{Pt}_{\mathrm{i}}:=$ & $P s_{i}:=$ \\
\hline 14.487 & 14.462 \\
\hline 14.493 & 14.456 \\
\hline 14.503 & 14.438 \\
\hline 14.420 & 14.317 \\
\hline 14.535 & 14.391 \\
\hline 14.554 & 14.354 \\
\hline 14.457 & 14.232 \\
\hline 14.575 & 14.315 \\
\hline 14.598 & 14.275 \\
\hline 14.530 & 14.129 \\
\hline 14.657 & 14.168 \\
\hline 14.680 & 14.151 \\
\hline
\end{tabular}

Uncertainty in Results

ENTER: Number of measurement sets averaged

ENTER: Number of test conditions to be evaluated

ENTER: Values for total and static pressures at each test condition

$$
\mathrm{Mo}_{\mathrm{i}}:=\sqrt{\left.5 \cdot\left[\frac{\mathrm{Ps}}{\mathrm{Pt}}\right)^{-\frac{2}{7}}-1\right]}
$$

Calculated Mach number $(\mathrm{Mo})$ at each test condition

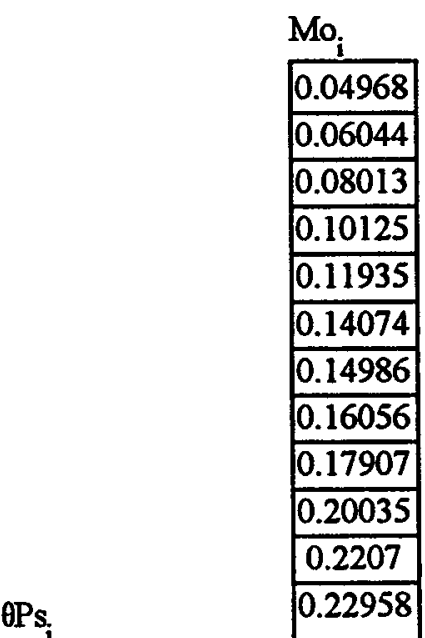

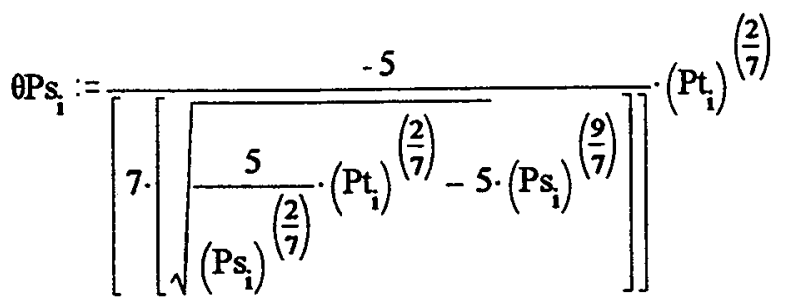

$\theta P s$
\begin{tabular}{|c|}
\hline-0.99468 \\
\hline-0.81811 \\
\hline-0.61818 \\
\hline-0.49377 \\
\hline-0.41706 \\
\hline-0.35499 \\
\hline-0.3364 \\
\hline-0.31237 \\
\hline-0.28122 \\
\hline-0.25436 \\
\hline-0.23066 \\
\hline-0.22218 \\
\hline
\end{tabular}

Mo sensitivity coeff.for static $\mathbf{P}$

12 
Page M.1.2

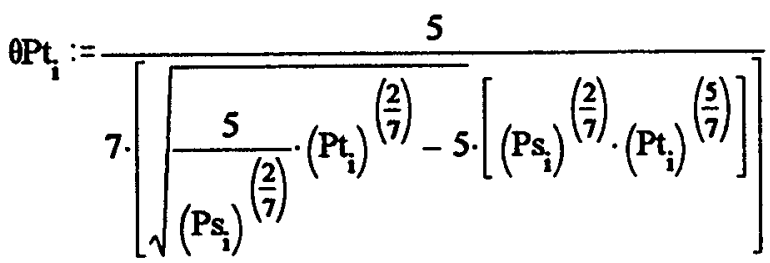

Mo sensitivity coeff.for total P

OPt.

0.99297

0.81602

0.61541

0.49024

0.41293

0.35011

0.33117

0.3068

0.275

0.24734

0.22296

0.21418

$\mathrm{UMoB}_{\mathrm{i}}:=\sqrt{\left[(\theta \mathrm{Pt} \cdot \mathrm{BPt})^{2}+(\theta \mathrm{Ps} \cdot \mathrm{BPs})^{2}+2 \cdot(\theta \mathrm{Pt}) \cdot(\theta \mathrm{Ps}) \cdot(\mathrm{BPtc}) \cdot(\mathrm{BPsc})\right]} \cdot \frac{1}{\mathrm{psi}} \quad \begin{aligned} & \text { Combined systematic } \\ & \text { component of Mo Uncert }\end{aligned}$ $\mathrm{UMOS}_{\mathrm{i}}:=\sqrt{(\theta \mathrm{Pt} \cdot \mathrm{SPt})^{2}+(\theta \mathrm{Ps} \cdot \mathrm{SPs})^{2}} \cdot \frac{1}{\mathrm{psi}}$

Combined precision component

$\mathrm{UMoB}_{i}$ of Mo uncertainty

UMoS
\begin{tabular}{|l|}
\hline 0.00105 \\
\hline 0.00087 \\
\hline 0.00065 \\
\hline 0.00052 \\
\hline 0.00044 \\
\hline 0.00037 \\
\hline 0.00035 \\
\hline 0.00033 \\
\hline 0.00029 \\
\hline 0.00027 \\
\hline 0.00024 \\
\hline 0.00023 \\
\hline
\end{tabular}

0.00127

0.00104

0.00079

0.00063

0.00053

0.00045

0.00043

0.00039

0.00035

0.00032

0.00029

0.00028

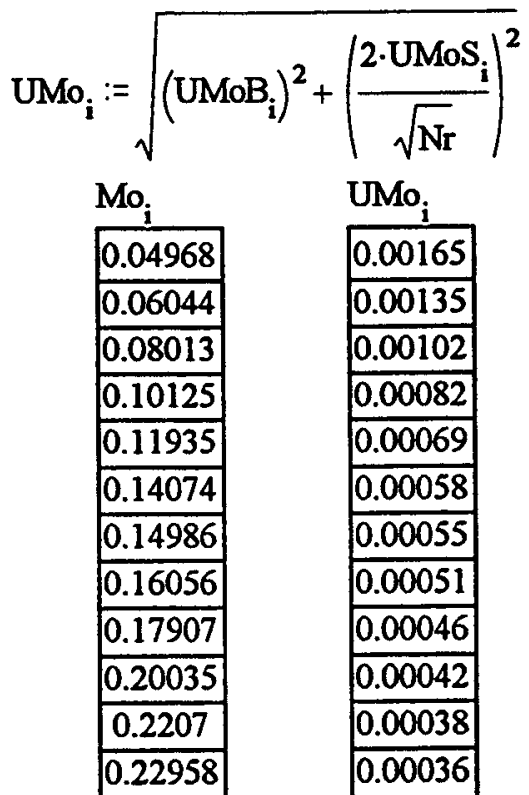

Combined uncertainty in Mach number (RSS)

\begin{tabular}{|l|}
\hline 0.00165 \\
\hline 0.00135 \\
\hline 0.00102 \\
\hline 0.00082 \\
\hline 0.00069 \\
\hline 0.00058 \\
\hline 0.00055 \\
\hline 0.00051 \\
\hline 0.00046 \\
\hline 0.00042 \\
\hline 0.00038 \\
\hline 0.00036 \\
\hline
\end{tabular}

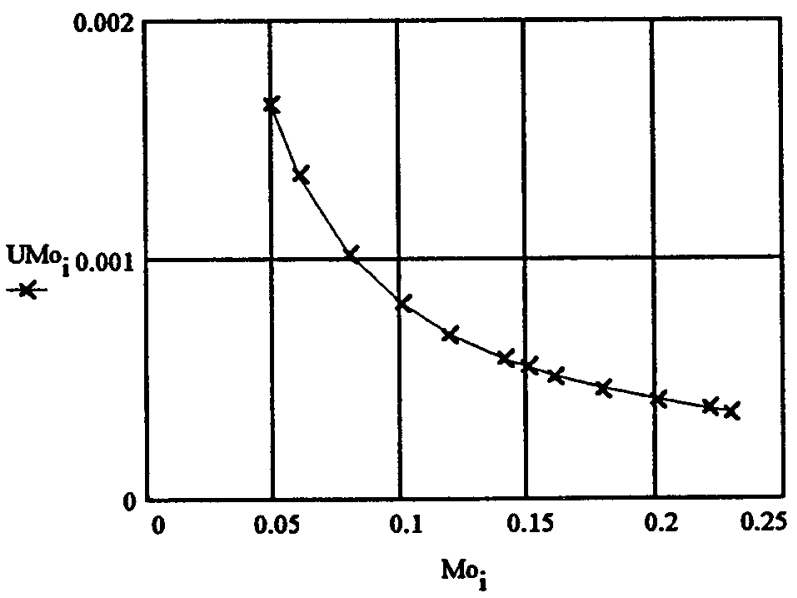

13 
780B System using Rackmount Modules

(+/- \%FS, except where noted)

\section{Digiquartz - Cortez III Calibration}

(Possible temperature variation during calibration: $+/-0.5 F$ )

\begin{tabular}{|c|c|c|}
\hline & $+1-6$ PSID & 15 PSIA \& I \\
\hline Repeatability & 0.0030 & 0.0015 \\
\hline Curve Fit Error & 0.0015 & 0.0030 \\
\hline Temp Error & 0.0015 & 0.0015 \\
\hline Ref Pressure Error & 0 & 0.0030 \\
\hline Ruska Deadweight (0.01\% Rdg) & 0.0100 & 0.0100 \\
\hline Temp Uncert Error & 0.0009 & 0.0009 \\
\hline Readout for Paroscientific & 0.0023 & 0.0023 \\
\hline
\end{tabular}

\section{Digiquartz Specifications}

B'2 - $0.001 \% / \%$ Temp error (per Cortez temp evaluation test)

B'3 - $0.005 \%$ Time base error (Estimate by PSD)

$B^{\prime} 4$ - $\quad 0.005 \% \quad$ Curve fit error (estimate by PSD)

S'1 - $0.005 \% \quad$ Repeatibility (Paroscientific specs)

S' 2 - 0.005\% Hysteresis (Paroscientific specs)

S'3 - 0.0005\% Counter Resolution (PSI specs)

\section{ESP Rackmount Module (S1600/S3200) Specifications}

S'4 - $0.010 \% \quad$ Repeatability (estimate by PSI)

S' 5 - $0.005 \% \quad$ Hysteresis (estimate by PSI)

B'6 - 0.02\%FS/\%F Thermal zero shift ( $5-500$ psid ) (S/N 1 to BO2037)

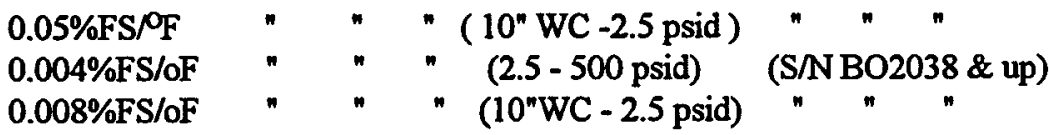

B'7 - 0.02\%FS/OF Thermal sensitivity shift ( 2.5 - $500 \mathrm{psid}$ ) (S/N 1 to BO2037)
$0.05 \% \mathrm{FS} /{ }^{\circ} \mathrm{F}$
" " " " (10" WC - 1 psid)
$0.003 \% \mathrm{FS} / \mathrm{oF}$
" (All Ranges)
(S/NBO2038 \& up)

\section{B DACU/PC Signal Processing \& Data Reduction Specifications}

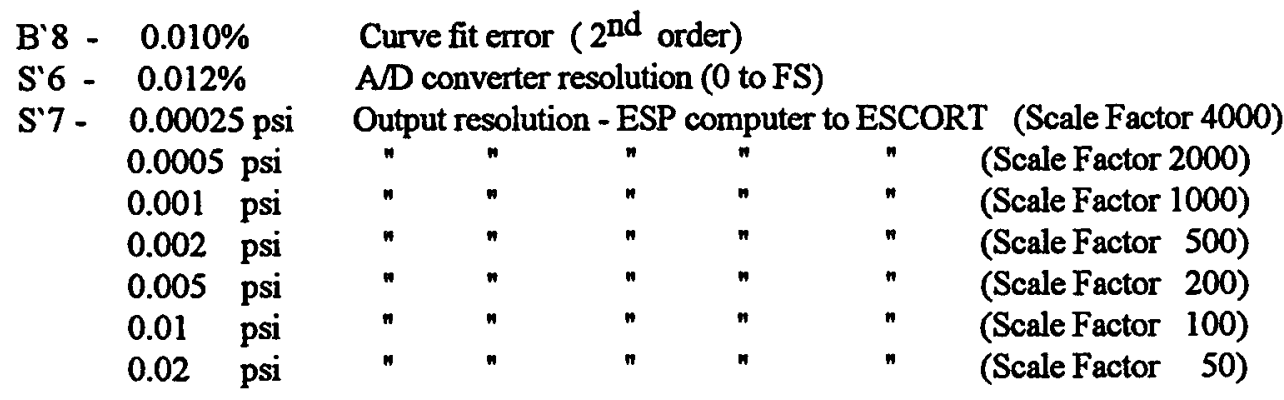


Public reporting burden for this collection of information is estimated to average t hout per response, including the time for reviewing instructions, searching existing data sources, gathering and maintaining the data needed, and completing and reviewing the collection of information. Send comments regarding this burden estimate of any other aspect of th collection of information, including suggestions for reducing this burden, to Washington Headquarters Services, Directorate tor information Operations and Reports, 1215 Jeft

\begin{tabular}{l|l|l|} 
1. AGENCY USE ONLY (Leave blank) & 2. REPORT DATE & 3. REPORT TYPE AND DATES COVERED
\end{tabular}

\begin{tabular}{|l|l|l} 
1. AGENCY USE ONLY (Leave blank) & $\begin{array}{c}\text { 2. REPORT DATE } \\
\text { July } 1995\end{array}$ & $\begin{array}{r}\text { 3. REPORT TYPE AND DATES COVERED } \\
\text { Final Contractor Report }\end{array}$
\end{tabular}

4. TITLE AND SUBTITLE

5. FUNDING NUMBERS

A PC Program for Estimating Measurement Uncertainty for Aeronautics

Test Instrumentation

6. AUTHOR(S)

Philip Z. Blumenthal

WU-505-62-82

C-NAS3-27186

7. PERFORMING ORGANIZATION NAME(S) AND ADDRESS(ES)

NYMA, Inc.

2001 Aerospace Parkway

8. PERFoRMING ORGANIZATION REPORT NUMBER

Brook Park, Ohio 44142

E-9759

9. SPONSORING/MONITORING AGENCY NAME(S) AND ADDRESS(ES)

National Aeronautics and Space Administration

Lewis Research Center

Cleveland, Ohio 44135-3191

10. SPONSORINGMONTTORING AGENCY REPORT NUMBER

NASA CR-198361

AIAA -95-3072

11. SUPPLEMENTARY NOTES

Prepared for the 31st Joint Propulsion Conference cosponsored by AIAA, ASME, SAE, and ASEE, San Diego, California, July 10-12, 1995. Project manager, Sandra L. Hardy, Aeropropulsion Facilities and Experiments Division, NASA Lewis Research Center, organization code 2800 , (216) 433-2278.

12a. DISTRIBUTIONAVAILABILTYY STATEMENT

12b. DISTRIBUTION CODE

Unclassified - Unlimited

Subject Category 09

This publication is available from the NASA Center for Aerospace Information, (301) 621-0390.

13. ABSTRACT (Maximum 200 words)

A personal computer program was developed which provides aeronautics and operations engineers at Lewis Research Center with a uniform method to quickly provide values for the uncertainty in test measurements and research results. The software package used for performing the calculations is Mathcad 4.0, a Windows version of a program which provides an interactive user interface for entering values directly into equations with immediate display of results. The error contribution from each component of the system is identified individually in terms of the parameter measured. The final result is given in common units, SI units, and percent of full scale range. The program also lists the specifications for all instrumentation and calibration equipment used for the analysis. It provides a presentation-quality printed output which can be used directly for reports and documents.

14. SUBJECT TERMS

Measurement uncertainty; Uncertainty analysis; Computer programs; Test measurements

17. SECURITY CLASSIFICATION OF REPORT

Unclassified
18. SECURITY CLASSIFICATION OF THIS PAGE

Unclassified
19. SECURITY CLASSIFICATION OF ABSTRACT Unclassified
15. NUMBER OF PAGES 16

16. PRICE CODE

A03

20. LIMITATION OF ABSTRACT 